\title{
Ocular Pharmacokinetics of a Novel Loteprednol Etabonate 0.4\% Ophthalmic Formulation
}

Lisa Schopf $\cdot$ Elizabeth Enlow $\cdot$ Alexey Popov

James Bourassa $\cdot$ Hongming Chen

To view enhanced content go to www.ophthalmology-open.com

Received: November 7, 2013 / Published online: February 4, 2014

(c) The Author(s) 2014. This article is published with open access at Springerlink.com

\section{ABSTRACT}

Introduction: Topical ophthalmic formulations of corticosteroids are commonly used to treat a variety of ocular diseases and conditions that have an inflammatory component. The purpose of this study was to evaluate the effect of the mucus-penetrating particle (MPP) technology on the pharmacokinetic profile of loteprednol etabonate in the ocular tissues of rabbits.

Methods: Forty-eight New Zealand White rabbits were randomly assigned to two groups ( $n=3$ rabbits or 6 eyes per time point) and treated with either the novel loteprednol etabonate MPP suspension formulation, $0.4 \%$ (LE-MPP $0.4 \%$ ), or the commercial Lotemax ${ }^{\circledR}$ brand loteprednol etabonate ophthalmic suspension, 0.5\% (Lotemax 0.5\%) (Bausch \& Lomb Incorporated, Inc., Rochester, NY, USA). Samples of aqueous humor, various ocular

Electronic supplementary material The online version of this article (doi:10.1007/s40123-014-0021-z) contains supplementary material, which is available to authorized users.

L. Schopf $(\bowtie) \cdot$ E. Enlow $\cdot$ A. Popov $\cdot$ J. Bourassa · H. Chen

Kala Pharmaceuticals, Inc., Waltham, MA, USA

e-mail: lisa.schopf@kalarx.com tissues, and plasma were collected from animals over a 12-h period after a single dose of the test articles. Loteprednol etabonate concentrations were assayed using liquid chromatography-tandem mass spectrometry (LC/MS/MS).

Results: Loteprednol etabonate was rapidly absorbed into ocular tissues following administration of either formulation. A higher ocular exposure was achieved using LE-MPP $0.4 \%$, with peak concentrations of approximately threefold higher in ocular tissues and the aqueous humor than Lotemax $0.5 \%$.

Conclusions: Administration of LE-MPP $0.4 \%$ improved loteprednol etabonate pharmacokinetic profile in ocular tissues of rabbits. The results of this study support the premise that the MPP technology can be used to enhance ocular exposure for topically applied therapeutic agents. Further studies to assess the clinical efficacy and safety of the LE-MPP formulation are warranted.

Keywords: Loteprednol etabonate; Mucous; Mucus; Ocular; Ophthalmic; Ophthalmology; Pharmacokinetic; Rabbit; Steroid; Topical 


\section{INTRODUCTION}

Ocular inflammation, if left untreated, can lead to temporary or permanent vision loss. Corticosteroids have been a mainstay in treating a variety of ocular diseases and conditions that have an inflammatory component due to their ability to elicit broad anti-inflammatory effects. Loteprednol etabonate, a corticosteroid that was developed for ophthalmic use, was designed using the soft drug concept in an effort to retain the therapeutic corticosteroid activity while minimizing adverse side effects $[1,2]$.

Loteprednol etabonate has been available for ophthalmic use in a variety of formulations for the past 15 years. Clinical studies evaluating the safety and efficacy of loteprednol etabonate have been performed for a number of ophthalmic conditions, including dry eye [3], seasonal allergic conjunctivitis [4], anterior uveitis [5], giant papillary conjunctivitis [6, 7], and treatment of pain and inflammation following cataract surgery [8-10]. Additionally, studies with various steroids assessing the risk of intraocular pressure (IOP) elevation, a common concern associated with ocular steroids, indicate that there may be reduced risk for loteprednol etabonate, as compared to other corticosteroids [11-13].

Topical application of therapeutic agents provides direct access to the target tissue; however, the ocular surface provides a set of unique challenges for topical penetration. Mechanisms to eliminate foreign material from the ocular surface include blinking, tear flow, and drainage through the nasolacrimal duct. Moreover, cornea and conjunctiva are naturally covered with a 3 - to $40-\mu \mathrm{m}$ layer of mucus [14-16]. The outer layer is comprised of secreted and other mucins (cleared rapidly by mucin turnover and blinking), whose primary role is to trap and eliminate allergens, pathogens and debris (including therapeutic particles) from the eye [17]. The inner layer (up to 500-nm thick) is formed by epitheliumtethered mucins (glycocalyx), which protect the corneal tissue from abrasive stress and are cleared less rapidly [17]. Drug carriers that can penetrate the rapidly cleared outer mucous layer and reach the slow-clearing glycocalyx are likely to reside at the ocular surface longer and facilitate drug release directly to the underlying tissue. However, conventional attempts to improve retention of agents on ocular surface often focus on designing ophthalmic formulations with higher viscosity, such as ointments or gels, which may have tolerability issues [18].

In an effort to circumvent the barrier presented by the mucous layers, novel formulations have been developed using a proprietary method to create mucuspenetrating nanoparticles [19]. This drug delivery platform allows for diffusion through the mucus and facilitates an even distribution of the nanoparticles across the ocular surface. The overall goal of the loteprednol etabonate mucus-penetrating particles suspension formulation, $\quad 0.4 \%$ (LE-MPP $0.4 \%$ ) is to improve drug penetration into tissues underlying the mucous barrier.

A previous report based on ${ }^{14} \mathrm{C}$-labeled loteprednol etabonate indicated that topical administration of Lotemax $0.5 \%$ suspension (Bausch \& Lomb Incorporated, Inc., Rochester, NY, USA) results in a relatively high distribution into the cornea, with reduced penetration into the aqueous humor and iris/ciliary body [20]. In this study, we investigate the effect of using a novel MPP formulation on the pharmacokinetic profile of loteprednol etabonate in the ocular tissues of rabbits. 


\section{MATERIALS AND METHODS}

A total of 48 male New Zealand White rabbits ranging from 4 to 5 months of age (weights ranged from 2.41 to $3.33 \mathrm{~kg}$ ) were used in this study. Rabbits were housed individually under standard conditions, provided water and dry rabbit feed pellets ad libitum, and were allowed 8 days to acclimatize to the facility conditions prior to study initiation. The experiment was conducted according to the standards of the Association of Research and Vision in Ophthalmology (ARVO) statement for the use of Animals in Ophthalmic and Vision Research. The study design was reviewed and approved by the facility Institutional Review Board. All institutional and national guidelines for the care and use of laboratory animals were followed.

A novel ophthalmic formulation of LE-MPP was prepared using a proprietary technology as described elsewhere [21]. Briefly, to generate LEMPP, a milling procedure was employed in which an aqueous dispersion containing coarse drug particles and an MPP-enabling surface-altering agent was milled with grinding medium until particle size was reduced to approximately $200 \mathrm{~nm}$ with a polydispersity index less than 0.15 as measured by dynamic light scattering. The LE-MPP $0.4 \%$ formulation is a suspension of loteprednol etabonate nanoparticles formulated with excipients approved by the US Food and Drug Administration (FDA) for ophthalmic use. The formulation is essentially isotonic with a nearneutral $\mathrm{pH}$ and, similarly to Lotemax suspension, contains $0.01 \%$ of benzalkonium chloride as the preservative. The LE-MPP formulation is shelf-stable (chemically and physically) at controlled room temperature $\left(15-25^{\circ} \mathrm{C}\right)$. The chemical purity of loteprednol etabonate in the final LE-MPP $0.4 \%$ formulation used in this study was greater than $97 \%$.
Lotemax ${ }^{\circledR}$-brand loteprednol etabonate ophthalmic suspension, $0.5 \%$ (Lotemax 0.5\%) was obtained from commercially available supplies (Bausch \& Lomb Incorporated, Inc., Rochester, NY, USA) and used as a comparator in this study.

Rabbits were randomly assigned to two treatment groups. After gentle shaking, a single 50 microliter $(\mu \mathrm{L})$ drop of either Lotemax $0.5 \%$ or LE-MPP $0.4 \%$ was administered to both eyes of each rabbit using a positive displacement pipette (Gilson, Inc., Middleton, WI, USA). The rabbits were gently restrained for approximately $2 \mathrm{~min}$ after the dosing to prevent the animals from shaking their heads or pawing at the eyes. At each of the following time points, $0.083,0.25,0.5,1.0$, 3.0, 6.0, and $12.0 \mathrm{~h}$ post-dosing, three rabbits from each treatment group were euthanized by intravenous barbiturate overdose and plasma samples were obtained. Both eyes from each rabbit were harvested, and samples were collected from the aqueous humor, conjunctiva, cornea, iris/ciliary body, and central retina.

Ocular irritation assessments were conducted according to the method reported by Draize et al. [22], for all animals prior to dosing (pre-dose) and prior to the necropsy.

All samples were assayed using liquid chromatography-tandem mass spectrometry (LC/MS/MS). The analysis for each matrix was performed separately, and tissue-specific standard curves were generated separately for both formulations. For animals treated with Lotemax $0.5 \%$, the analytical method had a lower limit of quantification (LLOQ) of $0.02 \mathrm{ng} /$ $\mathrm{mL}$ for plasma, $0.01 \mathrm{ng} / \mathrm{mL}$ for aqueous humor, $0.1 \mathrm{ng} / \mathrm{g}$ for cornea and iris/ciliary body, $2.0 \mathrm{ng} /$ $\mathrm{g}$ for conjunctiva, and $0.4 \mathrm{ng} / \mathrm{g}$ for retina. For animals treated with LE-MPP 0.4\%, the LLOQ was $0.02 \mathrm{ng} / \mathrm{mL}$ for plasma, $0.01 \mathrm{ng} / \mathrm{mL}$ for aqueous humor, $0.1 \mathrm{ng} / \mathrm{g}$ for cornea, $0.2 \mathrm{ng} / \mathrm{g}$ for conjunctiva and iris/ciliary body, and 
$0.4 \mathrm{ng} / \mathrm{g}$ for retina. Plasma and aqueous humor samples were diluted with control plasma or aqueous humor, respectively, and analyzed directly. Ocular tissue samples were weighed, homogenized, and diluted with methanol prior to analysis.

\section{Statistical Analysis}

The mean and the standard error of the mean (SEM) of loteprednol etabonate concentrations were calculated for each time point. WinNonlin ${ }^{\circledR}$ software (Pharsight Corporation, Mountain View, CA, USA), version 6.2.1, was used to calculate the pharmacokinetic parameters for each matrix: area under the concentration-time curve from the first time point to $12 \mathrm{~h}\left(\mathrm{AUC}_{0-\text { last }}\right)$; area under the concentration-time curve from the first time point extrapolated to infinity ( $\mathrm{AUC}_{0-\mathrm{inf}}$ ); maximum concentration observed $\left(C_{\max }\right)$, elimination half-life $\left(T_{1 / 2}\right)$; and time to reach maximum concentration $\left(T_{\max }\right)$. The log-linear trapezoidal rule was used to calculate AUCs. A "best fit" model was used to calculate the $T_{1 / 2}$. Prior to the calculations, any mean with a $\% \mathrm{CV}>100$ was checked for outliers at the $p<0.01$ level using the Grubbs' Test. If a value was confirmed as an outlier, it was not included in the pharmacokinetic calculation. Unpaired $t$ test was used to identify statistical significance between experimental groups receiving LE-MPP $0.4 \%$ to the comparator groups receiving Lotemax $0.5 \%$ using Prism version 6 software (GraphPad Software, San Diego, CA, USA). $P$ values less than 0.05 were considered significant.

\section{RESULTS}

Samples from all 48 rabbits (96 eyes) were included in the analysis for this study. Rabbits in all groups had normal appearing ocular tissues pre-dose and prior to necropsy. No abnormal scores were observed per the Draize method of scoring [22].

Concentrations of loteprednol etabonate in the aqueous humor are shown in Fig. 1. For

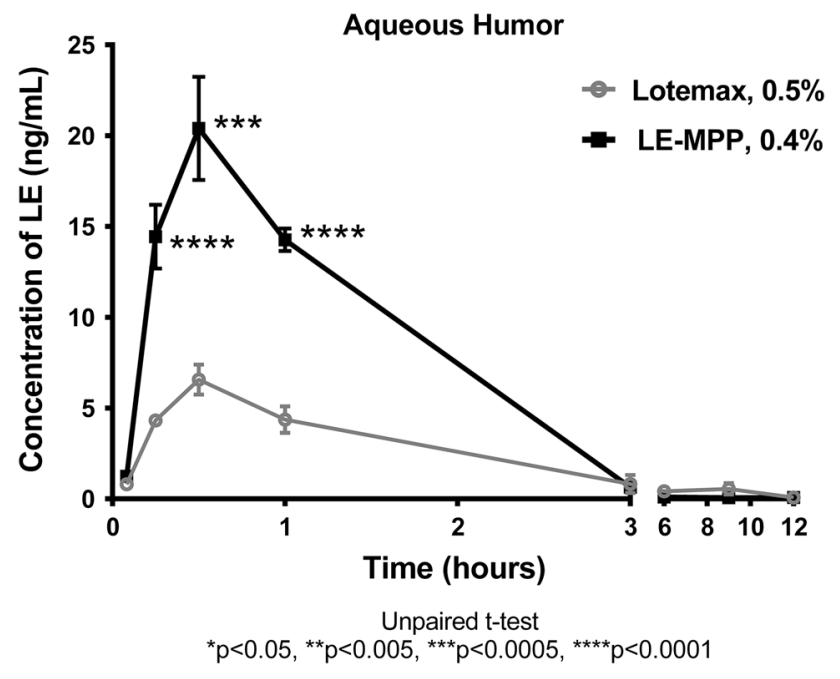

Fig. 1 Pharmacokinetic profile of loteprednol etabonate in rabbit aqueous humor. The mean loteprednol etabonate concentrations \pm SEM $(\mathrm{ng} / \mathrm{mL})$ for rabbits treated with

Lotemax $0.5 \%$ (circles), or LE-MPP $0.4 \%$ (squares) is depicted for the aqueous humor samples. The value shown for each time point is the mean \pm SEM for six samples 

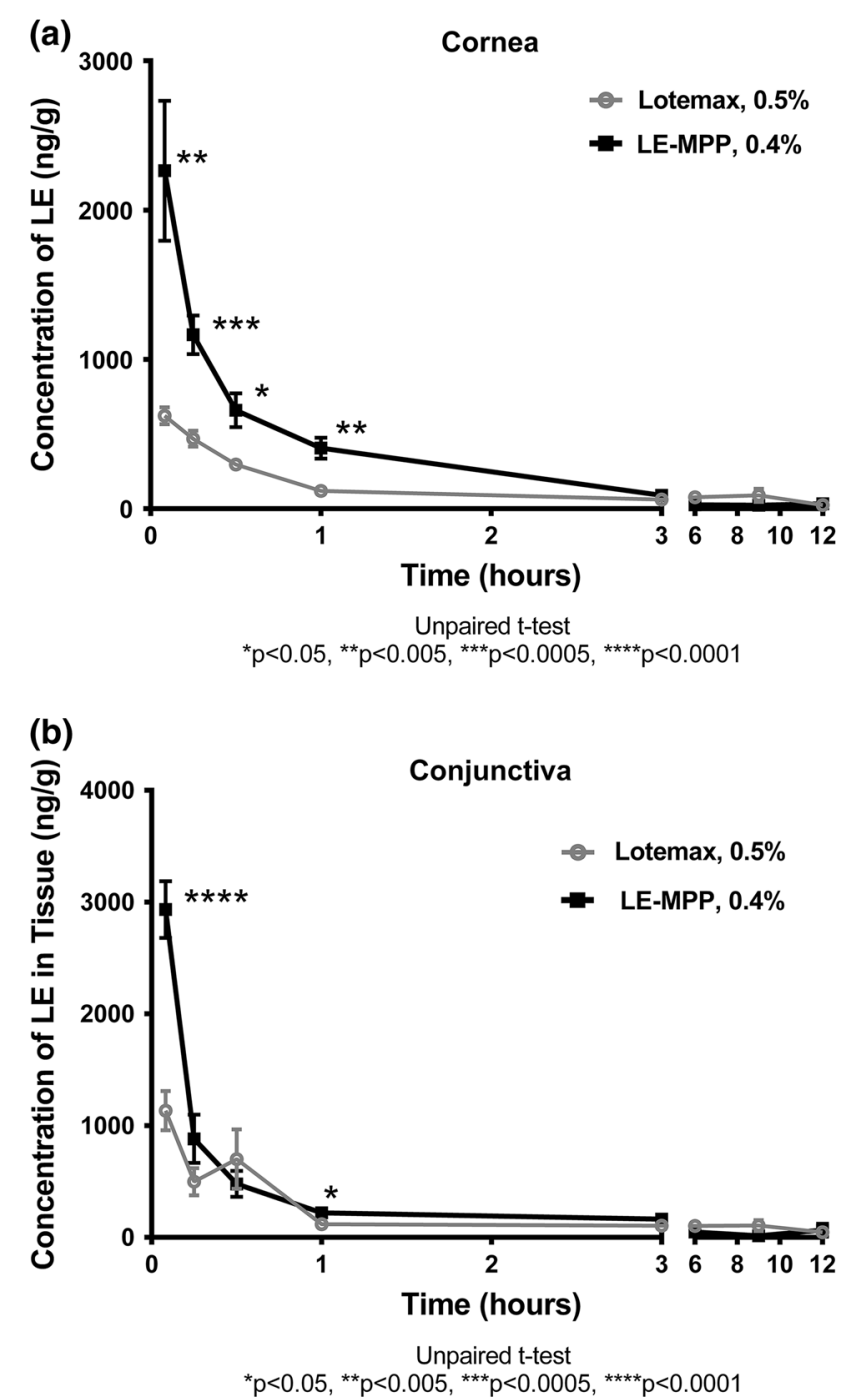

Fig. 2 Pharmacokinetic profile of loteprednol etabonate in rabbit cornea and conjunctiva. The mean loteprednol etabonate concentrations \pm SEM $(\mathrm{ng} / \mathrm{g})$ for rabbits treated

both formulations, $T_{\max }$ was observed at $0.5 \mathrm{~h}$ (30 min) after administration, with LE-MPP $0.4 \%$ showing an approximately threefold and twofold higher $C_{\max }$ and $\mathrm{AUC}_{0-12 \mathrm{~h}}$ respectively, than that of Lotemax $0.5 \%$.

Loteprednol etabonate concentrations in the cornea and conjunctiva following a single dose of either Lotemax $0.5 \%$ or LE-MPP $0.4 \%$ are shown in Fig. 2. The drug absorbed rapidly into the tissues from both formulations, with the with Lotemax $0.5 \%$ (circles), or LE-MPP 0.4\% (squares) is depicted for cornea (a) or conjunctiva (b). The value shown for each time point is the mean \pm SEM for six samples

highest levels observed at the earliest time point of $0.083 \mathrm{~h}(5 \mathrm{~min})$, then declining towards the LLOQ after the first $3 \mathrm{~h}$. Nevertheless, the peak levels in the cornea and conjunctiva were 3.6and 2.6-fold higher, respectively, for LE-MPP $0.4 \%$ than those for Lotemax $0.5 \%$. The

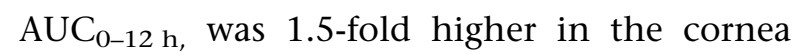
for LE-MPP $0.4 \%$ than that of Lotemax $0.5 \%$.

Concentrations of loteprednol etabonate in the iris/ciliary body and retina are shown in 

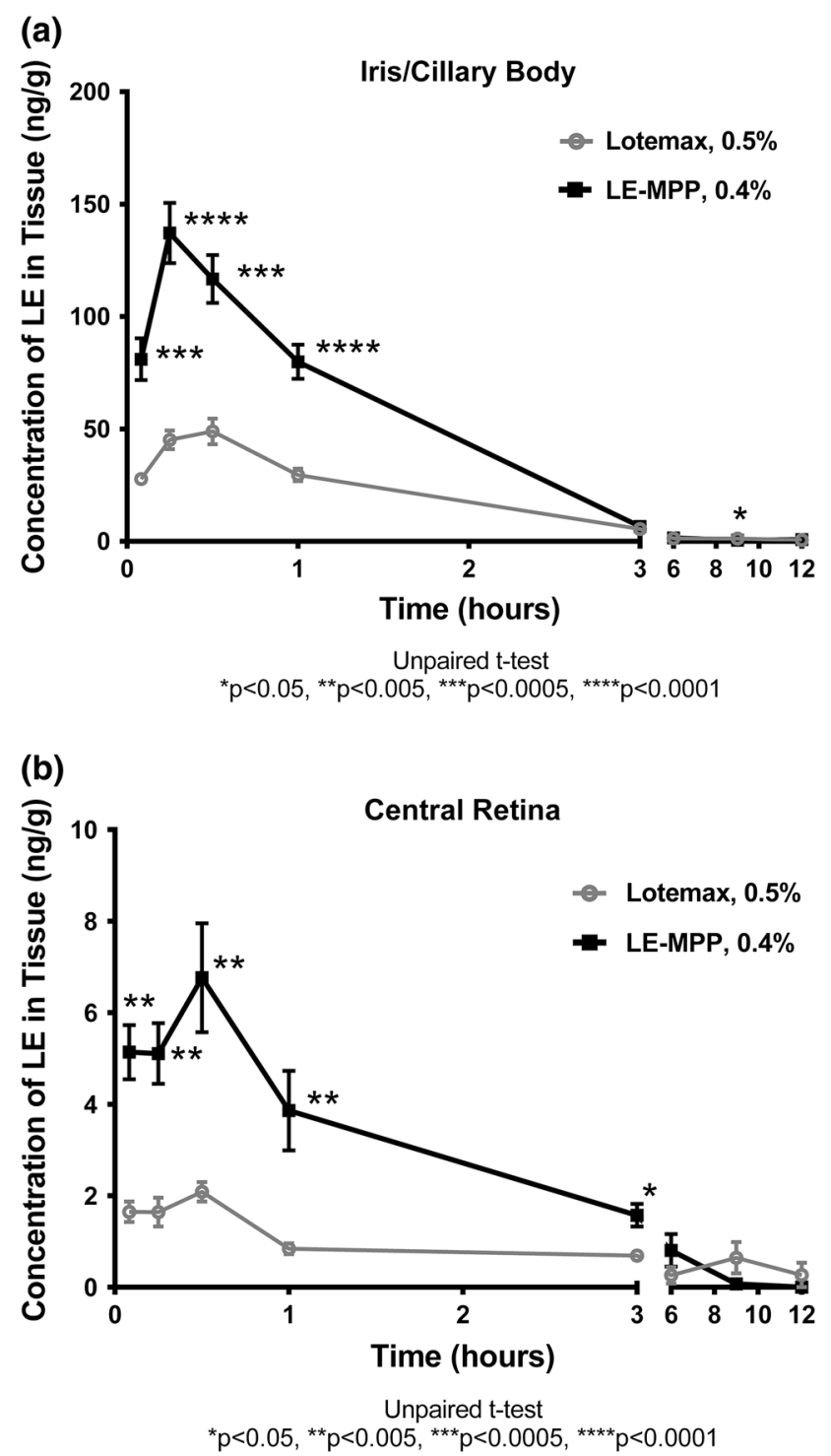

Fig. 3 Pharmacokinetic profile of loteprednol etabonate in rabbit iris/ciliary body and retina. The mean loteprednol etabonate concentrations \pm SEM ( $\mathrm{ng} / \mathrm{g}$ ) for rabbits treated with Lotemax $0.5 \%$ (circles), or LE-MPP $0.4 \%$ (squares) is

Fig. 3. $T_{\max }$ in the iris/ciliary body was observed at $0.25 \mathrm{~h}$ (15 $\mathrm{min})$ for LE-MPP $0.4 \%$, and at $0.5 \mathrm{~h}$ (30 min) for Lotemax $0.5 \%$ (Fig. 3a). $T_{\max }$ in the retina (Fig. $3 \mathrm{~b}$ ) occurred at $0.5 \mathrm{~h}(30 \mathrm{~min})$ for both formulations. $C_{\max }$ and $\mathrm{AUC}_{0-12 \mathrm{~h}}$ was approximately threefold and twofold higher, respectively, in animals treated with LE-MPP $0.4 \%$ than in those treated with Lotemax 0.5\% in the iris/ciliary body and retina. depicted for the iris/ciliary body (a) or retina $(\mathbf{b})$. The value shown for each time point is the mean \pm SEM for six samples

A summary of pharmacokinetic parameters in ocular tissues and plasma is presented in Table 1. A comparison of the values by tissue indicates a generally higher $C_{\max }$ and AUC for the LE-MPP $0.4 \%$ formulation, with the exception of conjunctiva, where the AUC values were similar between the two formulations. Plasma levels were also enhanced for the LE-MPP $0.4 \%$ formulation, 
Table 1 Pharmacokinetic parameters (mean \pm SEM) for loteprednol etabonate following a single ocular dose of Lotemax $0.5 \%$ or LE-MPP $0.4 \%$ in New Zealand White rabbits

\begin{tabular}{|c|c|c|c|c|c|}
\hline Sample & $\begin{array}{l}T_{1 / 2} \\
(\mathbf{h})\end{array}$ & $\begin{array}{l}T_{\max } \\
(\mathrm{h})\end{array}$ & $\begin{array}{l}C_{\max } \\
(\mathrm{ng} / \mathrm{mL} \text { or } \mathrm{ng} / \mathrm{g})\end{array}$ & $\begin{array}{l}\mathrm{AUC}_{0-\text { last }} \\
(\mathrm{ng} \mathrm{h} / \mathrm{mL} \text { or } \mathrm{ng} \mathrm{h} / \mathrm{g})\end{array}$ & $\begin{array}{l}\mathrm{AUC}_{0 \text {-inf }} \\
(\mathrm{ng} \mathrm{h} / \mathrm{mL} \text { or } \mathrm{ng} \mathrm{h} / \mathrm{g})\end{array}$ \\
\hline \multicolumn{6}{|l|}{ Aqueous humor } \\
\hline Lotemax $0.5 \%$ & 2.31 & 0.50 & $6 \pm 1$ & $14 \pm 2$ & 14 \\
\hline LE-MPP $0.4 \%$ & 1.57 & 0.50 & $20 \pm 3$ & $31 \pm 1$ & 31 \\
\hline \multicolumn{6}{|l|}{ Cornea } \\
\hline Lotemax $0.5 \%$ & 3.75 & 0.083 & $621 \pm 56$ & $1130 \pm 173$ & 1,270 \\
\hline LE-MPP $0.4 \%$ & 1.89 & 0.083 & $2260 \pm 470$ & $1670 \pm 130$ & 1,690 \\
\hline \multicolumn{6}{|l|}{ Conjunctiva } \\
\hline Lotemax $0.5 \%$ & 4.26 & 0.083 & $1130 \pm 177$ & $1610 \pm 238$ & 1,900 \\
\hline LE-MPP $0.4 \%$ & 1.92 & 0.083 & $2930 \pm 250$ & $1610 \pm 140$ & 1,630 \\
\hline \multicolumn{6}{|l|}{ Iris/Ciliary body } \\
\hline Lotemax $0.5 \%$ & 3.04 & 0.50 & $49 \pm 6$ & $91 \pm 5$ & 93 \\
\hline LE-MPP $0.4 \%$ & 1.49 & 0.25 & $137 \pm 14$ & $206 \pm 10$ & 208 \\
\hline \multicolumn{6}{|c|}{ Retina (center punch) } \\
\hline Lotemax $0.5 \%$ & 9.18 & 0.50 & $2.1 \pm 0.2$ & $6.9 \pm 1.3$ & 10 \\
\hline LE-MPP $0.4 \%$ & 1.55 & 0.50 & $6.8 \pm 1.2$ & $14.7 \pm 1.8$ & 15 \\
\hline \multicolumn{6}{|l|}{ Plasma } \\
\hline Lotemax $0.5 \%$ & 1.88 & 0.25 & $0.33 \pm 0.06$ & $0.76 \pm 0.06$ & 0.79 \\
\hline LE-MPP $0.4 \%$ & 1.71 & 0.25 & $1.19 \pm 0.26$ & $2.12 \pm 0.27$ & 2.20 \\
\hline
\end{tabular}

$\mathrm{AUC}_{0-\text { last }}$ : area under the concentration-time curve from the first time point to $12 \mathrm{~h}$; $\mathrm{AUC}_{0-\text { inf }}$ area under the concentration-time curve from the first time point to infinity (extrapolated); $C_{\max }$ maximum concentration observed; $T_{1 / 2}$ elimination half-life; $T_{\max }$ time to reach $C_{\max }$. Data presented as mean $\pm \mathrm{SEM}$, as appropriate. $C_{\max }$ is reported as either ng/ $\mathrm{mL}$ or $\mathrm{ng} / \mathrm{g}$ for fluid and tissue samples, respectively. Parameters pertaining to AUC are reported as either $\mathrm{ng} \mathrm{h} / \mathrm{mL}$ or $\mathrm{ng} \mathrm{h}$ / $\mathrm{g}$ for fluid and tissue samples, respectively

although overall systemic exposure is low for both formulations.

\section{DISCUSSION}

In this study, we observed that the preparation of a loteprednol etabonate ophthalmic suspension using the MPP technology resulted in an improved pharmacokinetic profile in the ocular tissues of New Zealand White rabbits when compared to Lotemax $0.5 \%$ suspension.
Administration of a single drop of the LE-MPP $0.4 \%$ formulation resulted in higher levels of loteprednol etabonate in the conjunctiva at the earliest time point of $0.083 \mathrm{~h}$ ( $5 \mathrm{~min}$ ). It should be noted that, based on the rapid dissolution of LE-MPP nanoparticles observed in vitro under sink conditions, the drug detected in the conjunctiva even at this earliest time point is likely molecularly absorbed in the tissue rather than imbedded in the tissue as intact nanoparticles. In addition, an approximately 
threefold higher $C_{\max }$ was observed in the aqueous humor, cornea, iris/ciliary body, and retina, indicating that LE-MPP $0.4 \%$ enabled a higher level of absorption in ocular tissues. The threefold higher $C_{\max }$ resulting from administration of LE-MPP $0.4 \%$ is particularly noteworthy as the formulation contains $20 \%$ less active drug than Lotemax $0.5 \%$. Although rabbits are the species of choice for topical pharmacokinetic studies, it remains to be seen if these enhancements translate into humans. These data support the premise that the MPP technology can enhance exposure of topically applied drugs.

The results of this study generally agree with the previously published distribution profile of loteprednol etabonate in ocular tissues following topical administration, in that the highest levels of drug exposure are found on the ocular surface (corneal and conjunctival tissues) shortly after administration, while comparatively reduced levels of loteprednol etabonate penetrate past the ocular surface (aqueous humor, iris/ciliary body, and retina) [20]. However, the LC/MS/MS analytical method employed in the present study (compared to the use of radio-labeled drug material in the previous study), allows for a direct quantitation of loteprednol etabonate in ocular tissues.

Topical delivery of therapeutic agents offers the distinct benefit of application of a high concentration of the active agent at the desired site of action. In the case of ophthalmic formulations, relatively high doses of drug are easily delivered to the ocular surface. However, retention time of an ophthalmic formulation on the ocular surface limits the effectiveness of a product after instillation. Nanoparticles have the potential to improve ocular exposure from topical administration; however, this effort had been undermined by adhesion of virtually all synthetic nanoparticles to the ocular mucous layer, which protects the eye by effectively trapping and rapidly clearing foreign particles from the ocular surface $[17,23]$. Ocular residence time of such nanoparticles is, therefore, limited by the turnover rate of the peripheral ocular mucus, typically on the order of seconds to minutes. To enhance topical ocular delivery, drug carriers must avoid entrapment by, and readily penetrate through, the mucous layer of the eye. The increase in exposure of ocular tissues to loteprednol etabonate with LE-MPP $0.4 \%$ as compared to Lotemax $0.5 \%$ in this study indicates that MPP formulation of loteprednol etabonate may have resulted in a longer retention time on the ocular surface.

\section{CONCLUSION}

The LE-MPP 0.4\% formulation used in this study produced increased levels of loteprednol etabonate in ocular tissues and fluids when compared to Lotemax $0.5 \%$ suspension. The enhanced pharmacokinetic profile of loteprednol etabonate seen in this study supports further investigation into whether the LE-MPP formulation may allow for a reduction in the dosing frequency and/or dosing concentration in clinical applications. Further studies to assess the efficacy and safety of the LE-MPP formulation for clinical applications are warranted.

\section{ACKNOWLEDGMENTS}

Sponsorship and article processing charges for this study was funded by Kala Pharmaceuticals, Inc. We also acknowledge that all pharmacokinetic studies were conducted at PharmOptima, LLC (Portage, MI, USA). We thank Kim Brazzell and Kristina Burgard (employees of Kala Pharmaceuticals) for their 
critical review of this manuscript. All authors had full access to all the data in this study and take complete responsibility for the integrity of the data and accuracy of the data analysis. All named authors meet the ICMJE criteria for authorship for this manuscript, take responsibility for the integrity of the work as a whole, and have given final approval for the version to be published.

Conflict of interest. L. Schopf is an employee of Kala Pharmaceuticals, which is developing a novel ophthalmic formulation of loteprednol etabonate.

E. Enlow is an employee of Kala Pharmaceuticals, which is developing a novel ophthalmic formulation of loteprednol etabonate.

A. Popov is an employee of Kala Pharmaceuticals, which is developing a novel ophthalmic formulation of loteprednol etabonate.

J. Bourassa is an employee of Kala Pharmaceuticals, which is developing a novel ophthalmic formulation of loteprednol etabonate.

$\mathrm{H}$. Chen is an employee of Kala Pharmaceuticals, which is developing a novel ophthalmic formulation of loteprednol etabonate.

Compliance with ethics guidelines. The experiment was conducted according to the standards of the Association of Research and Vision in Ophthalmology (ARVO) statement for the use of Animals in Ophthalmic and Vision Research. The study design was reviewed and approved by the facility Institutional Review Board. All institutional and national guidelines for the care and use of laboratory animals were followed.

Open Access. This article is distributed under the terms of the Creative Commons Attribution Noncommercial License which permits any noncommercial use, distribution, and reproduction in any medium, provided the original author(s) and the source are credited.

\section{REFERENCES}

1. Bodor $\mathrm{N}$, Loftsson $\mathrm{T}$, Wu WM. Metabolism, distribution, and transdermal permeation of a soft corticosteroid, loteprednol etabonate. Pharm Res. 1992;9(10):1275-8.

2. Bodor N, Buchwald P. Ophthalmic drug design based on the metabolic activity of the eye: soft drugs and chemical delivery systems. AAPS J. 2005;7(4):E820-33.

3. Pflugfelder SC, Maskin SL, Anderson B, et al. A randomized, double-masked, placebo-controlled, multicenter comparison of loteprednol etabonate ophthalmic suspension, $0.5 \%$, and placebo for the treatment of keratoconjunctivitis sicca in patients with delayed tear clearance. Am J Ophthalmol. 2004;138(3):444-57.

4. Dell SJ, Schulman DG, Lowry GM, Howes J. A controlled evaluation of the efficacy and safety of loteprednol etabonate in the prophylactic treatment of seasonal allergic conjunctivitis. Loteprednol allergic conjunctivitis study group. Am J Ophthalmol. 1997;123(6):791-7.

5. Loteprednol Etabonate US Uveitis Study Group. Controlled evaluation of loteprednol etabonate and prednisolone acetate in the treatment of acute anterior uveitis. Am J Ophthalmol. 1999;127(5): 537-44.

6. Asbell P, Howes J. A double-masked, placebocontrolled evaluation of the efficacy and safety of loteprednol etabonate in the treatment of giant papillary conjunctivitis. CLAO J. 1997;23(1):31-6.

7. Friedlander MH, Howes J. A double-masked, placebo controlled evaluation of the efficacy and safety of loteprednol etabonate in the treatment of giant papillary conjunctivitis. Loteprednol etabonate giant papillary conjunctivitis study group I. Am J Ophthalmol. 1997;123(4):455-64.

8. Stewart R, Horwitz B, Howes J, Novack GD, Hart K. Double-masked, placebo-controlled evaluation of loteprednol etabonate $0.5 \%$ for postoperative inflammation. Loteprednol Etabonate Postoperative Inflammation Study Group I. J Cataract Refract Surg. 1998;24(11):1480-9.

9. Loteprednol Etabonate Postoperative Inflammation Study Group 2. A double-masked, placebo-controlled evaluation of $0.5 \%$ loteprednol etabonate in the treatment of postoperative inflammation. Ophthalmology. 1998;105(9):1780-6.

10. Comstock TL, Paterno MR, Singh A, Erb T, Davis E. Safety and efficacy of loteprednol etabonate ophthalmic ointment $0.5 \%$ for the treatment of 
inflammation and pain following cataract surgery. Clin Ophthalmol. 2011;5:177-86.

11. Bartlett JD, Horwitz B, Laibovitz R, Howes JF. Intraocular pressure response to loteprednol etabonate in known steroid responders. J Ocul Pharmacol. 1993;9(2):157-65.

12. Novack GD, Howes J, Crockett RS, Sherwood MB. Change in intraocular pressure during long-term use of loteprednol etabonate. J Glaucoma. 1998; 7(4):266-9.

13. Comstock TL, DeCory HH. Advances in corticosteroid therapy for ocular inflammation: loteprednol etabonate. Int J Inflam. 2012;2012: 789623.

14. King-Smith PE, Fink BA, Fogt N, Nichols KK, Hill RM, Wilson GS. The thickness of the human precorneal tear film: evidence from reflection spectra. Invest Ophthalmol Vis Sci. 2000;41(11): 3348-59.

15. Prydal JI, Artal P, Woon H, Campbell FW. Study of human precorneal tear film thickness and structure using laser interferometry. Invest Ophthalmol Vis Sci. 1992;33(6):2006-11.

16. Prydal JI, Campbell FW. Study of precorneal tear film thickness and structure by interferometry and confocal microscopy. Invest Ophthalmol Vis Sci. 1992;33(6):1996-2005.
17. Mantelli F, Argueso P. Functions of ocular surface mucins in health and disease. Curr Opin Allergy Clin Immunol. 2008;8:477-83.

18. Gaudana R, Anathula HK, Parenky A, Mitra AK. Ocular drug delivery. AAPS J. 2010;12(3):348-60.

19. Lai SK, O'Hanlon DE, Harrold S, Man ST, Wang YY, Cone R, Hanes J. Rapid transport of large polymeric nanoparticles in fresh undiluted human mucus. PNAS. 2007;104:1482-7.

20. Druzgala P, Wu WM, Bodor N. Ocular absorption and distribution of loteprednol etabonate, a soft steroid, in rabbit eyes. Curr Eye Res. 1991;10(10): 933-7.

21. Popov A, Enlow EM, Bourassa J, Gardner CR, Chen $\mathrm{H}$, Ensign $\mathrm{LM}$ et al., inventors; Kala Pharmaceuticals, Inc., Johns Hopkins University, assignees. Pharmaceutical nanoparticles showing improved mucosal transport. World patent application WO/2013/166385. 2013 Nov 7.

22. Draize JH, Woodard G, Calvery HO. Methods for the study of irritation and toxicity of substances applied topically to the skin and mucous membranes. J Pharmacol Exp Ther. 1944;82: 377-90.

23. Ludwig A. The use of mucoadhesive polymers in ocular drug delivery. Adv Drug Deliver Rev. 2005;57:1595-639. 